\title{
Commentary: Because we can
}

\author{
Waël C. Hanna, MDCM, MBA, FRCSC
}

In this issue of JTCVS Techniques, Galvaing and colleagues ${ }^{1}$ present a challenging but gratifying case of triple-sleeve right upper lobectomy, where reconstruction of the bronchus, pulmonary artery, and vena cava was necessary for the success of resection. The patient, a 66year-old woman, had refused chemotherapy and was not a surgical candidate for a pneumonectomy. Although the caval resection and reconstruction was not planned, it was rapidly executed due to the appearance of superior vena cava syndrome intraoperatively. The patient lived 4 years after the initial resection-a true feat without chemotherapy-and died from a cause not related to lung cancer.

The report is rich in technical lessons learned from this case, the likes of which only 4 others have been reported. One cannot help but wonder why that is. Certainly, it would not be because of the paucity of T4 lung tumors. Could it be because many of these patients are receiving a pneumonectomy? Or is it because such operations have been tried and were not successful? So how do we measure the success of such cases?

The most valuable lesson that I learned from this case is not technical. It is that the feasibility of these cases is measured by a large number of critical steps-patient selection, surgeon selection, investigations, execution, and postoperative care. However, the success of these cases is measured only by one critical metric-survival. The authors waited 4 years to publish this report and only did so after it was determined that this patient will never have lung cancer recurrence. In other words, the technical lessons from this case are only worth sharing if the operation was beneficial to the patient.

\footnotetext{
Division of Thoracic Surgery, McMaster University, Hamilton, Ontario, Canada Disclosures: The author reported no conflicts of interest.

The Journal policy requires editors and reviewers to disclose conflicts of interest and to decline handling or reviewing manuscripts for which they may have a conflict of interest. The editors and reviewers of this article have no conflicts of interest.

Received for publication Aug 2, 2020; revisions received Aug 2, 2020; accepted for publication Aug 4, 2020; available ahead of print Aug 11, 2020.

Address for reprints: Waël C. Hanna, MDCM, MBA, FRCSC, St Joseph's Healthcare Hamilton, 50 Charlton Ave E, Juravinski Tower, Suite T2105 F, Hamilton, Ontario L8N4A6, Canada (E-mail: hannaw@mcmaster.ca).

JTCVS Techniques 2020;4:328

2666-2507

Copyright (c) 2020 The Authors. Published by Elsevier Inc. on behalf of The American Association for Thoracic Surgery. This is an open access article under the CC BY-NCND license (http://creativecommons.org/licenses/by-nc-nd/4.0/).

https://doi.org/10.1016/j.xjtc.2020.08.004
}

We continue to push the technical boundaries of our specialty with multiple success stories, but we should never lose focus of why we do what we do. We don't do it because we can. We do it because it saves a life, for more than 90 days. Sometimes, the difference is not clearly obvious.

\section{Reference}

1. Galvaing G, Sassi S, Dagenais F, Conti M. Triple-sleeve lobectomy for non-small cell lung cancer: lessons from a case. J Thorac Cardiovasc Surg Tech. 2020;4: $323-5$. 